\title{
A time for reflection and change
}

would like to introduce myself to you, as the new editor of this journal. I am a physiotherapist, mother, grandmother, sister, relation and friend. As a clinician I have a specia] interest in developmental paediatrics and early intervention. Academically, I have a $\mathrm{PhD}$ from the University of the Witwatersrand. I retired from the Chair of Physiotherapy at the Witwatersrand University and Head of the Physiotherapy Department at the Johannesburg Hospital at the end of 1996. I have for the past seven years been President of the College of Physiotherapy and am at present an Honorary Lecturer in the Physiotherapy Department at the University of the Witwatersrand.

It may well be a coincidence that at a time when I was mulling over what to say in the first editorial that I ripped off the cover of the August edition of PhysioForum to find Desmond Tutu, chairman of the TRC looking straight at me. I wondered whether I had a confession to make. I asked the questions "Is my slate clean?" and "Have I committed any crimes?"

I consider myself to be a highly moral and ethical person, non-racist, non-sexist and non-discriminatory in every way. Nevertheless I had to ask myself the question: "Where was I during the Apartheid Era?" I was working in the civil service in special schools, clinics and hospitals. I must have been aware of the fact that these facilities were segregated and that I was serving a small privileged group of children. I must have known that some of my colleagues were queuing in the early hours of the

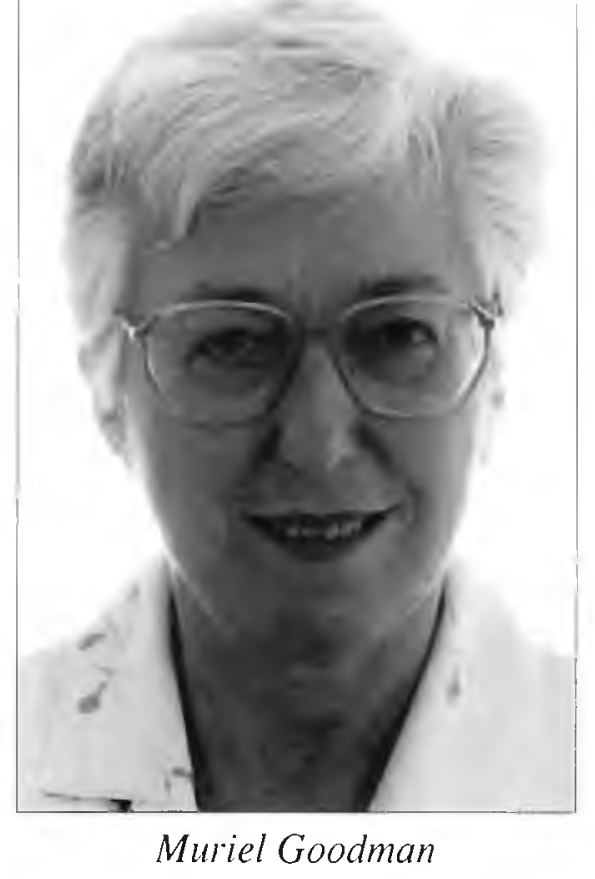

morning to catch segregated buses from wayout townships in order to get to work while I was still asleep. For me the injustice of it all was that my pay cheque received at the end of each month, albeit very modest, was more than that of many of my colleagues. with the same qualifications putting in the same amount of work.

What reparations can I offer in a spirit of reconciliation? I would like to dedicate myself to making this journal representative of all members of the SASP. I would like to reach out to physiotherapy assistants and encourage them to write to us and tell us what they do, think and feel. As part of the African continent, 1 believe we have a unique contribution to make to the physiotherapy profession worldwide. While we may not have the academic and scientific experience of the western world, I think that we are well on the way to developing primary health services which are low cost and effective in reaching disadvantaged communities.

I would like to invite physiotherapists throughout Africa to publish in our journal and thereby share their invaluable hands-on experience. I would like to make contact with the many South African physiotherapy graduates who have left our country for whatever reason, and ask them to publish in our journal and tell us where they are, what they are doing and how they are feeling.

I hope that our mailbox will be overflowing with correspondence and information relevant to physiotherapists in Africa and the world at large.

This journal like any publication can only be as good as the input of its readers - interest, input and feedback being the key to success. I urge you to make yourselves heard through correspondence by means of publications, case studies, interesting personal experience, suggestions and feedback on the relevance of this journal.

The South African Journal of Physiotherapy is the official mouthpiece of the SASP and hopefully will become a forum where we can openly challenge and exchange ideas. This must surely be the way to growth and development!

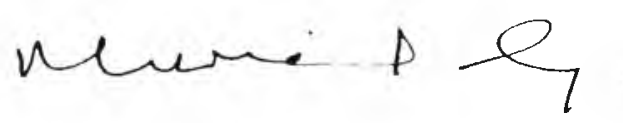

Muriel Goodman - Editor 